\section{Apoio das Universidades aos Spin-Offs Acadêmicos nas Fases de Earlye Later Stage}

\author{
Cibele Lopes Souto Maior-Cabanne, Xênia L'amour Campos Oliveira e \\ Rivanda Meira Teixeira
}

\section{RESUMO}

Pesquisas sobre spin-offs acadêmicos demonstram diferentes tipos de apoio prestado pelas universidades nas fases de desenvolvimento early e later stage. Este estudo tem como objetivo analisar as formas de apoio concedido pelas universidades aos spin-offs acadêmicos nessas fases de desenvolvimento. Foi realizado um estudo de casos múltiplos com dois spin-offs acadêmicos, um de universidade pública e outro de universidade privada, localizados na cidade de Aracaju, no Estado de Sergipe. Os spin-offs acadêmicos foram selecionados em função da fase de desenvolvimento, um deles com menos de quatro anos de criação (early stage), e outro com mais de quatro anos (later stage). Pode-se observar que o apoio fornecido pelas universidades aos spin-offs analisados foi considerado deficiente nas duas fases. Dessa forma, não foi observado participação ativa da universidade na obtenção de recursos, disponibilização de contatos ou oferta de disciplinas voltadas ao empreendedorismo. O mérito das universidades consistiu na disponibilização das incubadoras e, por meio delas, cursos de capacitação e infraestrutura. Sugere-se que é necessário conscientizar as universidades sobre a importância do estímulo ao empreendedorismo e do suporte da universidade aos primeiros anos do spin-off, que são os mais críticos.

Palavras-Chave: empreendedorismo; spin-off acadêmico; apoio da universidade; early stage; later stage.

\section{Universities Support to Spin-Offs Academics in Early and Later Stages}

\section{ABSTRACT}

Research on academic spin-offs demonstrate different types of support provided by universities in the early and later development stages. This study aims to analyze the forms of support provided by universities to academic spin-offs in these development stages. It was conducted a study of multiple cases with two academic spin-offs: one from a public university and other from a private university, both located in the city of Aracaju, Sergipe State, Brazil. Academic spin-offs were selected based on the development stage, one has less than four years of creation (early stage), and the other more than four years (later stage). It was seen that the support provided by universities to spin-offs in the analysed cases was considered poor in both phases. Thus, there was no active participation of the university in obtaining resources, providing contacts or offer courses focused on entrepreneurship. The universities merit was based on the provision of incubators and, through them, training courses and infrastructure. It is suggested that it is necessary to raise awareness in universities about the importance of encouraging entrepreneurship and university support on the first year of the spin-off, which are the most critical.

Keywords: entrepreneurship; academic spin-off; university support; early stage; later stage.

Recebido em: 09/12/2017 Aprovado em: 30/05/2018 Última Modificação: 02/10/2018

Check for updates

Cibele Lopes Souto

Maior-Cabanne (iD,

Programa de Pós-Graduação em

Administração, Universidade Federal

de Sergipe, Brasil.

Mestre em Administração pela

Universidade Federal de Sergipe,

Brasil.

cibelelsmc@gmail.com

Xênia L'amour Campos

\section{Oliveira (iD),}

Curso de Administração, Faculdade

Maurício de Nassau, Brasil.

Mestre em Administração pela

Universidade Federal de Sergipe,

Brasil.

xenia.Ico@gmail.com

Rivanda Meira Teixeira (iD, Programa de Pós-Graduação em Administração da Universidade Federal do Paraná, Brasil.

Doutora em Administração pela Cranfield University, Inglaterra.

rivandateixeira@gmail.com 


\section{Introdução}

Os principais mecanismos através dos quais a universidade e os pesquisadores transferem conhecimentos são as conferências e publicações científicas, a formação de força de trabalho qualificada e a comercialização do conhecimento. Quanto à última, a forma mais visível de comercialização da pesquisa universitária se dá através de spin-offs (Landry, Amara, \& Rherrad, 2006). Spin-offs acadêmicos ocorrem quando novas empresas são criadas para explorar comercialmente conhecimento, tecnologia ou os resultados de pesquisas desenvolvidas dentro de uma universidade (Pirnay \& Surlemont, 2003). Shane (2004) considera que estes são um mecanismo de comercialização da propriedade intelectual produzida nas instituições acadêmicas.

Em outras palavras, são a expressão do empreendedorismo dentro do ambiente universitário, sendo fundamental para preencher as lacunas entre o mundo acadêmico e de negócios (Abramson, Encarnacao, Reid, \& Schmoch, 1997 como citado em Walter, Auer, \& Ritter, 2006). Ao promover essa ligação entre os dois mundos, os spin-offs acadêmicos demonstram sua importância para criação de novos empregos (Borges, Porto, \& Dias, 2017; Carayannis, Rogers, Kurihara, \& Allbritton, 1998; Steffensen, Rogers, \& Speakman, 2000); transferência e comercialização de inovações tecnológicas; aprofundamento da relação negócios-academia; e reestruturação de economias regionais (Soetanto \& Van Geenhuizen, 2015).

Os estudos existentes sobre o tema foram iniciados nos Estados Unidos e englobam eixos diversos, como: tipologias dos spin-offs acadêmicos (Pirnay \& Surlemont, 2003); processo de formação e evolução (Carayannis et al., 1998; Gilsing, Van Burg, \& Romme, 2010; Pérez \& Sánchez, 2003; Vohora, Wright, \& Lockett, 2004); crescimento e inovação (Dahlstrand, 1997; Rickne, 2000); envolvimento em rede (Soetanto \& Van Geenhuizen, 2015; Walter et al., 2006); transformação dos resultados acadêmicos em valor econômico (Ndonzuau, Pirnay, \& Surlemont, 2002); e, mais recentemente, sobre a formação de capital social (Borges \& Filion, 2013; Soetanto \& Van Geenhuizen, 2015). No entanto, tais estudos incidem, principalmente, sobre a criação e o desenvolvimento de curto prazo dos spin-offs acadêmicos (Treibich, Konrad, \& Truffer, 2013), negligenciando o relacionamento da universidade com essas empresas (Berbegal-Mirabent, Ribeiro-Soriano, \& García, 2015; Bezerra, Borges, \& Andreassi, 2017; Ferreira, Reis, Paula, \& Pinto, 2017).

Considerando que o processo de desenvolvimento do spin-off é afetado pelo contexto, as taxas de insucesso, a criação de empregos e a velocidade de seu desenvolvimento são diferentes quando a universidade oferece apoio (Pirnay \& Surlemont, 2003; Rasmussen, Mosey, \& Wright, 2011). Essas formas de suporte incluem, por exemplo, programas de apoio à criação dos spin-offs, que estimulam a exploração de tecnologias criada pelos cientistas, fornecem proteção à propriedade intelectual, além de oferecer assistência durante o processo de criação da empresa (Berbegal-Mirabent et al., 2015).

A distinção entre as universidades públicas e privadas também afeta a criação de spin-offs. A principal diferença entre essas instituições é o 
modelo de financiamento. Enquanto as universidades públicas dependem de recursos governamentais, as universidades privadas recebem recursos dos estudantes e outras fontes de financiamento (Berbegal-Mirabent et al., 2015). As universidades públicas também parecem ter políticas menos flexíveis e menos focadas quando se trata da transferência de tecnologia da universidade para a indústria, enquanto as universidades privadas parecem ser mais eficientes, por sua maior proximidade com outras empresas (Siegel, Waldman, \& Link, 2003), além de serem mais orientadas ao mercado (Belenzon \& Schankerman, 2007). Apesar de o tipo de instituição afetar a criação de empresas pelas universidades, a pesquisa sobre o tema ainda tem sido pouco explorada (Berbegal-Mirabent et al., 2015).

Diante desse contexto, esse estudo tem como objetivo analisar as formas de apoio concedido pelas universidades aos spin-offs acadêmicos, nas fases de desenvolvimento early e later stage, conforme classificação de Soetanto e Van Geenhuizen (2015). Em particular, buscou-se identificar em que fase de desenvolvimento se encontram os spin-offs acadêmicos e as formas de apoio disponibilizadas pelas universidades nessas fases. Dentre as formas de apoio são destacadas: a existência de disciplinas voltadas ao empreendedorismo; a realização de eventos, palestras e seminários; disponibilização de infraestrutura, laboratórios e equipamentos; a existência de incubadora ligada à universidade; o contato com os professores e com os alunos; a obtenção de recursos financeiros, patentes e acesso à network da universidade. Em complemento, optou-se por examinar dois tipos de spin-offs, um deles proveniente de universidade pública e o outro de universidade privada, de modo a comparar as diferenças entre as formas de apoio provido por instituições com características distintas. Esse estudo contribui ao investigar em duas universidades, uma pública e outra privada, três aspectos dos spin-offs acadêmicos ainda escassos na literatura: o relacionamento do spin-offs com as universidades de origem (Berbegal-Mirabent et al., 2015; Ferreira et al., 2017), o tipo dessas instituições (Berbegal-Mirabent et al., 2015) e o apoio que elas oferecem (Pirnay \& Surlemont, 2003).

\section{Quadro Teórico}

\section{Spin-Offs acadêmicos}

Spin-offs, também chamados de spinouts ou spin-outs, são empresas que surgem de outras. Basicamente, um funcionário deixa uma organização levando consigo tecnologia e conhecimento, e os utiliza para criar uma nova empresa (Carayannis et al., 1998). As organizações das quais eles derivam são variadas, como laboratórios de pesquisa, empresas privadas ou públicas e institutos de pesquisa. Assim, eles podem ser classificados de acordo com a organização de origem e de onde o empreendedor adquiriu sua experiência (Pérez \& Sánchez, 2003). Com base nisso, uma categorização bastante aceita os divide em dois grandes tipos: acadêmicos, que surgem de instituições de educação superior, e corporativos, derivados de empresas em geral (Dahlstrand, 1997). 
No começo do século, pesquisas semelhantes consideravam diferentes definições de spin-offs acadêmicos e, portanto, apontavam resultados conflitantes. Pirnay e Surlemont (2003), então, apresentaram a seguinte explicação: os spin-offs acadêmicos são empresas criadas com o propósito de explorar comercialmente o conhecimento, tecnologia, ou resultados de pesquisa existentes dentro da universidade. Os autores, de acordo com as pesquisas de McQueen e Wallmark (1982 como citado em Pirnay \& Surlemont, 2003), declaram como pré-requisitos para uma empresa ser considerada um spin-off acadêmico três critérios: os fundadores devem vir de uma instituição de ensino superior (alunos, professores ou funcionários); a atividade da companhia deve ser baseada em ideias técnicas geradas no ambiente universitário; e a transferência da universidade para a empresa deve ser direta.

Um spin-off acadêmico é, portanto, fruto do empreendedorismo dentro de uma universidade (Berbegal-Mirabent et al., 2015) e, geralmente, apresenta uma postura mais ativa em relação à transferência de tecnologia que os spin-offs corporativos, já que as empresas tentam manter as pesquisas e tecnologias para si (Gübeli \& Doloreux, 2005). A transferência de tecnologia se dá de duas maneiras: primeiro, da organização de origem para a nova empresa e, em seguida, para o cliente final (Pérez \& Sánchez, 2003). De acordo com Pirnay e Surlemont (2003), é o empreendedorismo, através da criação de uma nova empresa, que diferencia os spin-offs das formas tradicionais de transferência de conhecimento academiamercado, tais como aquelas apresentadas por Berbegal-Mirabent et al. (2015): licenciamento e patenteamento, parcerias universidade-indústria e contratos de pesquisa com empresas. São essas características, seus resultados e possibilidades, que têm chamado a atenção dos pesquisadores para essa modalidade, em detrimento de outras (Bekkers, Gilsing, \& Van Der Steen, 2006; Bercovitz \& Feldmann, 2006; Lockett, Siegel, Wright, \& Ensley, 2005).

A importância dos spin-offs acadêmicos vai além da transferência de tecnologia. Eles estão associados ao desenvolvimento econômico (Bathelt, Kogler, \& Munro, 2010; O'Shea, Chugh, \& Allen, 2008; Soetanto \& Van Geenhuizen, 2015; Vincett, 2010) e, assim, também geram empregos (Carayannis et al., 1998; Pérez \& Sánchez, 2003; Steffensen et al., 2000; Walter et al., 2006). Isso se traduz no número crescente de empresas de sucesso originadas no ambiente universitário, dentre elas, encontram-se corporações bilionárias, como Google, Gatorade e Cirrus Logic (Di Gregorio \& Shane, 2003).

Vários estudos têm abordado a propensão de uma universidade gerar spin-offs (Di Gregorio \& Shane 2003; Gras Lapera, Solves, Jover, \& Azuar, 2008; Lockett, Wright, \& Franklin, 2003; Powers \& Mcdougall, 2005), como promover o empreendedorismo nas universidades (Bailetti, 2011; Bezerra et al., 2017) e políticas públicas de incentivo à criação (Van Geenhuizen \& Soetanto, 2009). Já outros retratam que é crucial que haja estímulo ao empreendedorismo acadêmico, tanto partindo das universidades, quanto dos governos (Hess \& Siegwart, 2013). 
No entanto, os spin-offs acadêmicos se deparam com diversas dificuldades que são relatadas na literatura. Dentre elas, destaca-se a pouca experiência dos empreendedores, além de seu conhecimento limitado e acesso restrito aos mercados (Lockett \& Wright, 2005); a exigência de submissão da empresa aos padrões e regras da universidade, o que pode limitar seu desenvolvimento (Rasmussen, 2006; obstáculos na obtenção de recursos e habilidades necessárias para transformar a ideia em um produto pronto para o mercado (Siegel, Waldman, Atwater, \& Link, 2003; Shane, 2004; Bathelt et al., 2010); interesses muitas vezes conflitantes entre os envolvidos: universidade, empreendedores, professores, etc. (Boardman \& Ponomariov, 2009; McAdam \& McAdam, 2008; Mustar et al., 2006); maior risco, em comparação a outras start-ups, devido à presença de tecnologia e inovação nos produtos/serviços (Clarysse, Wright, Lockett, Van de Velde, \& Vohora, 2005; Vohora et al., 2004); e a maior complexidade na definição do real potencial de crescimento da empresa, devido à dificuldade em obter financiamentos (Clarysse, Wright, Lockett, Mustar, \& Knockaert, 2007; Wright, Lockett, Clarysse, \& Binks, 2006).

Para Soetanto e Van Geenhuizen (2015), esses problemas acontecem porque o ambiente acadêmico ainda tem pouca afinidade com as atividades comerciais, pois, para muitos pesquisadores universitários, o avanço tecnológico em si é mais importante do que a exploração comercial da nova tecnologia. Devido a isso, investidores externos podem considerar os spinoffs acadêmicos uma forma de investimento pouco atraente, uma vez que empreendedores geralmente buscam financiamento na própria universidade. Em consequência, várias são as instituições que auxiliam a universidade no suporte a essas empresas: centros de pesquisa, governos, agências de fomento, incubadoras de empresa, parques tecnológicos, clusters e etc. (Hoffman, Mais, \& Amal, 2010), através de investimentos públicos e privados (Phan, Siegel, \& Wright, 2005).

Considerando essas perspectivas e baseando-se em extensa revisão de literatura, O'Shea et al. (2008) identificaram alguns aspectos que são determinantes para um indivíduo empreender ou não em uma universidade. Segundo esses autores, atributos empreendedores estão diretamente relacionados à criação dessas empresas e aspectos como personalidade, motivação e disposição têm um papel influente nesse tipo particular de empreendedorismo, em conjunto com as habilidades e disposições pessoais. Quanto aos determinantes por parte da universidade para que haja empreendedorismo acadêmico, esse estudo demonstra que a qualidade da universidade e de seus pesquisadores, além de cultura institucional de incentivo à comercialização, influenciam positivamente o número de empresas criadas. Lockett e Wright (2005) destacam ainda que, no Reino Unido, a quantidade de spin-offs acadêmicos criados está relacionada diretamente ao investimento da universidade em pesquisa e desenvolvimento. Powers e McDougall (2005) corroboram esse achado e, em complemento, O'Shea, Allen, Chevalier e Roche (2005) descobriram que as universidades com um financiamento voltado para as áreas de ciências biológicas, ciência da computação e química formam um maior número de empresas. 


\section{Fases de desenvolvimento dos spin-offs}

Tendo em vista o crescente número de spin-offs acadêmicos criados e de políticas que promovem a formação dos mesmos, Van Geenhuizen e Soetanto (2009) realizaram estudo sobre os obstáculos que restringem o crescimento dessas empresas e como eles variam ao longo do tempo. Para esses autores, a característica sobre a qual os spin-offs diferem é a fase de desenvolvimento em que se encontram, pois vivenciam processo de interação dinâmica devido aos diversos atores envolvidos, seus objetivos e níveis de envolvimento. Rasmussen (2011) afirma que esses negócios passam por mudanças como: modelo de negócio, à medida em que os empreendedores adquirem mais conhecimentos gerenciais e técnicos; composição da equipe de empreendedores; e recursos necessários enquanto a empresa se desenvolve. Diretamente relacionados a essas mudanças, os obstáculos ao crescimento examinados pelos pesquisadores são apresentados no Quadro 01 e relacionam-se ao mercado, gestão, finanças, estrutura física e governo.

\begin{tabular}{ll}
\hline \multicolumn{1}{c}{ Relacionados } & \multicolumn{1}{c}{ Especificação } \\
\hline Mercado & Conhecimentos em Marketing; Habilidades em vendas; Estabelecimento de uma base de clientes \\
Gestão & Incertezas com as quais deve-se lidar; Gerenciamento (overload) \\
Finanças & Fluxo de caixa, Capital de investimento; Investimentos em pesquisa e desenvolvimento \\
Estrutura Física & Acomodação, Infraestrutura; Distância (dos fornecedores, mercados etc.) \\
Governo & Regulação, burocracia \\
\hline
\end{tabular}

Quadro 01: Obstáculos ao Crescimento

Fonte: Adaptado de Van Geenhuizen e Soetanto (2009).

A partir da análise desses empecilhos, Van Geenhuizen e Soetanto (2009) estabeleceram duas fases de desenvolvimento: early stage e later stage. A primeira compreende os spin-offs que foram criados há quatro anos ou menos e a segunda refere-se àqueles com mais de quatro anos. Esse marco de quatro anos de criação foi definido porque os achados da pesquisa demonstraram que após essa idade o número de obstáculos ao crescimento diminuiu consideravelmente.

\section{Apoio da universidade aos spin-offs}

O papel da universidade quanto às atividades de comercialização vem mudando e, juntamente aos mecanismos governamentais e institucionais de apoio, um maior número de empresas universitárias vem sendo criadas (Djokovic \& Souitaris, 2008). Os spin-offs são criados através de um "impulso da demanda" e têm representado um mecanismo relevante para estimular a economia (Berbegal-Mirabent et al., 2015, p. 2272) e o empreendedorismo (Borges et al. 2017), além de manifestarem um desempenho melhor quando comparados a outros tipos de empresas (Koster, 2006), especialmente em estágios iniciais (Andersson \& Keppler, 2013).

O estudo de Berbegal-Mirabent et al. (2015) investigou os fatores que explicam a criação de spin-offs universitários, com base na Visão Baseada em Recursos (RBV) e apontou três fatores: as atividades de suporte, recursos 
de capital humano e as infraestruturas de apoio. Além desses fatores, os autores acrescentaram a análise do tipo de universidade, pública ou privada, fator esse que também influencia a criação dessas empresas.

O acesso ao capital e recursos financeiros também são fatores que fazem parte das atividades de suporte da universidade (Berbegal-Mirabent et al., 2015) e estudos demonstram que a falta desse acesso é uma das dificuldades enfrentadas pelos empreendedores (Borges Jr., Filion, \& Simard, 2010; Rasmussen et al., 2011), principalmente empreendedores jovens, que têm maior dificuldade em contratar financiamentos em bancos (Borges, Filion, \& Simard, 2008). O acesso a esses recursos é mais importante no início da empresa do que nas outras fases de seu desenvolvimento, já que o investimento de capital é necessário para financiar o crescimento da empresa (Fini, Grimaldi, \& Sobrero, 2009; Ndonzuau et al., 2002).

Para Bailetti (2011), existem algumas ações que a universidade deve implementar para fomentar a atividade empreendedora: ajudar os empreendedores a obter recursos externos; conseguir acesso aos consumidores em potencial, parceiros e investidores; e fornecer recursos a estudantes que possuem oportunidades de negócios viáveis. Essas ações salientam a importância da universidade no que diz respeito à obtenção de recursos com o intuito de apoiar a atividade empreendedora dos estudantes. Os recursos de capital humano irão incluir consultores técnicos que auxiliarão na criação do spin-off, além de outros profissionais habilitados que irão suportar a criação da empresa, uma vez que, "começar um negócio requer treinamento e avaliação” (Berbegal-Mirabent et al., 2015, p. 2273).

Outra fonte de capital humano que pode ser oferecida pela universidade diz respeito ao contato com outros alunos. Mueller (2011) destaca a necessidade de o ambiente universitário promover oportunidades para que os estudantes tenham contato com outros alunos com intenções empreendedoras. Ademais, de acordo com Bailetti (2011), a universidade também deve apoiar os estudantes para que os mesmos empreguem outros alunos em sua empresa, além de promover a colaboração entre eles.

A infraestrutura de apoio integra as incubadoras, que são as responsáveis por apoiar o spin-off durante seu desenvolvimento inicial, oferecendo aos empreendedores serviços e facilidades, além de promover o compartilhamento de experiências e fomentar uma atmosfera criativa (Berbegal-Mirabent et al., 2015). As incubadoras, segundo Raupp e Beuren (2009), oferecem um ambiente propício ao desenvolvimento da empresa, facilitando o acesso aos conhecimentos e às entidades de financiamento. Além disso, a presença delas nas universidades impulsiona a criação de spin-offs (O'Shea et al., 2005) e reduz a probabilidade de fracasso das empresas ligadas a elas (Rothaermel \& Thursby, 2005).

Além das incubadoras, a infraestrutura de apoio abrange a existência de parques tecnológicos, que proporcionam um ambiente para criação, exploração e compartilhamento de conhecimentos, além de auxiliar na criação de empresas baseadas em inovação (Berbegal-Mirabent et al., 2015). As empresas localizadas nesses parques apresentam também uma maior produtividade em relação à pesquisa (Siegel, Westhead, \& Wright, 2003). 
Pesquisas mostraram ainda que estudantes que vivenciaram programas de educação empreendedora são empresários bem mais sucedidos do que aqueles que não tiveram esse tipo de educação (Bernstein \& Carayannis, 2012). O ensino de empreendedorismo e inovação também pode representar estímulos aos alunos a abrirem seu próprio negócio, além de desenvolver conhecimentos e competências de como fazê-lo. Por esses motivos, incorporar esses tópicos nos currículos das universidades tem sido um instrumento importante na criação de negócios de sucesso (Harkema \& Schout, 2008). Além disso, as universidades devem formular programas que associem a experiência em sala de aula com experiências de mercado, favorecendo uma rede de contatos dos estudantes com empresários experientes (Mueller, 2011).

Os métodos de ensino também são tão importantes quanto o conteúdo dos cursos, já que os mesmos também podem influenciar as intenções empreendedoras dos estudantes. Assim, os educadores devem exercer o papel de facilitadores, para que seus alunos tenham experiências relevantes (Mueller, 2011). Em estudo realizado por Fini et al. (2009) apontou que, entre os fatores individuais que influenciam a criação de novas empresas por acadêmicos italianos, a melhoria do status acadêmico é o incentivo mais importante, ou seja, a valorização desses profissionais impulsiona seu envolvimento em atividades empreendedoras. A realização de eventos ligados à inovação e ao empreendedorismo, como cursos, palestras, seminários e fóruns, também pode auxiliar na capacitação dos empreendedores acadêmicos, além de agregar conhecimentos quanto ao gerenciamento de seus negócios (Luz, 2012).

No processo de criação de empresas, as redes sociais exercem um papel de protagonistas, pois fornecem benefícios como o aumento na identificação de oportunidades pelos empreendedores, proporcionam o acesso a vários tipos de recursos, geram vantagens sobre o tempo que o empreendedor necessita para explorar oportunidades de mercado e constituem uma fonte de referências e status (Nicolaou \& Birley, 2003). O contato dos estudantes com empreendedores também pode estimular a atividade empreendedora nas universidades (Bailetti, 2011), já que a ligação com a universidade permite que o empreendedor acadêmico dê credibilidade a sua empresa, auxiliando a convencer alguns contatos de que a empresa que está sendo criada e que sua tecnologia é confiável. Essa ligação também promove o acesso a determinados contatos, recursos tecnológicos e apoio na universidade, além de acesso a recursos financeiros fora dela (Borges \& Filion, 2013).

No processo de criação de spin-offs acadêmicos, um indicador de crescimento e sucesso é o registro de patentes (Clarysse et al., 2007). Spin-offs que possuem patentes têm maiores facilidades no acesso a capital de risco (Clarysse, Wright, \& Van De Velde, 2011). A disponibilidade de escritórios para transferência de tecnologia pelas universidades fornece apoio aos pesquisadores na divulgação dos resultados de suas pesquisas, apresenta os empreendedores aos investidores e promovem e gerenciam a propriedade intelectual da universidade (Berbegal-Mirabent et al., 2015). Ademais, a profissionalização desses escritórios aumenta a qualidade das patentes elaboradas e, consequentemente, o apoio financeiro aos spin-offs que detêm essas patentes (Clarysse et al., 2011). 
Entre os recursos que a universidade também pode disponibilizar aos estudantes como forma de suporte, estão o acesso a laboratórios e equipamentos (Steffensen et al., 2000; Callan, 2001; Ndonzuau et al., 2002). Um estudo realizado por Landry et al. (2006) sobre a criação de spin-offs por universidades canadenses mostrou que o acesso dos pesquisadores a grandes laboratórios aumentou a probabilidade na criação dessas empresas da mesma maneira que os fatores anos de experiência em pesquisa e o acesso aos recursos de grandes universidades.

\section{Procedimentos Metodológicos}

Este estudo adota uma abordagem qualitativa, assumindo que a realidade social é fruto da interpretação das percepções dos indivíduos (Bryman \& Bell, 2015). A estratégia de pesquisa aplicada foi a de estudo de caso que, de acordo com Eisenhardt (1989), tem seu foco voltado para o entendimento das dinâmicas de um fenômeno em sua singularidade. Para Yin (2015) o estudo de caso mostra-se como uma estratégia mais adequada quando o pesquisador tem pouco controle sobre os eventos estudados e quando esses estão inseridos em um determinado contexto do cotidiano. Foram analisados dois casos de spin-offs acadêmicos, um de universidade pública e outro de universidade privada, localizados na cidade de Aracaju, no Estado de Sergipe. Os spinoffs acadêmicos foram selecionados em função da fase de desenvolvimento, na qual um deles se encontrava com quatro anos de idade ou menos (early stage) e o outro com mais de quatro anos (later stage) de criação. O quadro 02 apresenta algumas informações sobre os casos selecionados.

\begin{tabular}{ccccccc}
\hline Empresa & Sócios & Fase & Início & Atuação & Universidade & Incubadora \\
\hline Avatar B2B & 2 & Early stage & 2014 & Tecnologia da Informação & Pública & SergipeTec \\
Lumentech & 1 & Later stage & 2004 & Jogos eletrônicos & Privada & ITEC \\
\hline
\end{tabular}

Quadro 02: Características das empresas estudadas

Fonte: Elaborado pelos autores (2017).

Utilizou-se como técnica de coleta de dados entrevistas semiestruturadas com os empreendedores de cada um dos spin-offs, já que esse tipo de entrevista permitiria uma maior flexibilidade ao pesquisador (Saunders, Lewis, \& Thornhill, 2009). Além disso, foi realizada pesquisa documental de informações contidas nos sites das empresas, como ramo de atividade, principais clientes e serviços ou produtos oferecidos pela empresa. As entrevistas duraram em média cinquenta minutos, foram gravadas e posteriormente transcritas para facilitar análise. Foram entrevistados os dois empreendedores que criaram os spin-offs.

A análise dos casos seguiu as recomendações de Eisenhardt (1989), nas quais deve-se seguir duas etapas: 1) a análise de cada caso em particular e 2) a análise entre os casos, através da técnica de cross-case analysis, em que foram observadas as suas semelhanças e diferenças. Essa comparação foi guiada por categorias analíticas previamente estabelecidas, com base na revisão da literatura, como mostra o Quadro 03. 


\begin{tabular}{|c|c|}
\hline Categorias de análise & Elementos de análise \\
\hline Fases de desenvolvimento & $\begin{array}{l}\text { Early stage: compreende os spinoffs criados há quatro anos ou menos (Van Geenhuizen \& Soetanto, 2009). } \\
\text { Later stage: abrange os spinoffs com mais de quatro anos de criação. Após esse tempo, o número de } \\
\text { obstáculos ao crescimento diminui consideravelmente (Van Geenhuizen \& Soetanto, 2009). }\end{array}$ \\
\hline \multirow{7}{*}{$\begin{array}{l}\text { Formas de apoio da } \\
\text { universidade }\end{array}$} & $\begin{array}{l}\text { Disponibilização de disciplinas voltadas ao empreendedorismo (Harkema \& Schout, 2008; Bernstein \& } \\
\text { Carayannis, 2012; Mueller, 2011) } \\
\text { Realização de eventos (Luz, 2012) } \\
\text { Disponibilização de infraestrutura: laboratórios, equipamentos (Steffensen et al., 2000; Landry et al., 2006) } \\
\text { Incubadora (0'Shea et al., 2005; Rothaermel \& Thursby, 2005; Berbegal-Mirabent et al., 2015; Borges et } \\
\text { al., 2017) }\end{array}$ \\
\hline & Network fornecido pela universidade (Nicolaou \& Birley, 2003; Bailetti, 2011) \\
\hline & Apoio dos alunos (Bailetti, 2011; Mueller, 2011) \\
\hline & Contato com os professores (Fini et al., 2009; Mueller, 2011) \\
\hline & Obtenção de recursos financeiros (Ndonzuau et al., 2002; Fini et al., 2009) \\
\hline & Patente (Clarysse et al., 2011; Berbegal-Mirabent et al., 2015; Borges et al., 2017) \\
\hline & $\begin{array}{l}\text { Diferença entre universidade pública e universidade privada (Siegel, Waldman, \& Link, 2003; Belenzon \& } \\
\text { Schankerman, 2007;) }\end{array}$ \\
\hline
\end{tabular}

Quadro 03: Categorias analíticas e elementos de análise

Fonte: Elaborado pelos autores com base na revisão da literatura (2017).

\section{Descrição dos casos}

Inicialmente, apresenta-se a descrição de cada caso, tendo como base as categorias analíticas adotadas neste estudo apresentadas no Quadro 03. Em seguida, a análise comparativa entre os casos foi realizada com o intuito de enfatizar as semelhanças e diferenças entre eles, bem como compará-los com a teoria.

\section{O Caso da Avatar B2B}

A Avatar B2B é uma empresa de consultoria e serviços na área de Tecnologia e Inovação criada em 2014 e está em estágio de incubação. Um dos proprietários, o "Empreendedor A", é formado em Sistemas para Internet, fez pós-graduação na mesma área e é aluno do mestrado em Propriedade Intelectual na Universidade Federal de Sergipe. A empresa surgiu como forma de desenvolver um aplicativo para o segmento de bares e restaurantes de nome "IBAR", como explica:

Tinha um amigo meu que trabalhava no SEBRAE e ele atendia muitas empresas do setor de alimentos, bares e restaurantes, e aí surgiu a possibilidade da gente desenvolver uma inovação pra esse segmento. [...]. Então a ideia foi desenvolver uma inovação que atendesse esse segmento para poder desenvolver a empresa. 
Atualmente, a Avatar B2B possui quinze colaboradores e oferece serviços de treinamento, desenvolvimento de softwares, sites, aplicativos, consultoria em Tecnologia da Informação, gestão em mídias sociais, entre outros serviços ligados à área de Tecnologia da Informação (TI). De acordo com o entrevistado, os serviços ofertados ajudam em sua manutenção: "É bem custoso manter. [...] pra gente conseguir manter o projeto de inovação a gente acaba fazendo outros serviços de forma paralela pra conseguir ter recursos pra manter a empresa".

No início do negócio, o apoio da universidade não foi determinante, mas o conhecimento técnico dos proprietários relacionado à ideia de desenvolver um produto foi de suma importância. A promoção de eventos como palestras e seminários sobre inovação e empreendedorismo foi importante para inspirar e trazer conhecimentos, assim como a oferta de disciplinas sobre essas temáticas, sobretudo no curso de mestrado frequentado pelo entrevistado. Para o entrevistado, tais disciplinas, além do conhecimento, "trouxeram inspiração também, a partir dos cases que eram apresentados". O empreendedor não recorda se em sua graduação essas temáticas foram abordadas na grade curricular.

Sobre a disponibilização de infraestrutura pela universidade, como laboratórios e equipamentos, era de conhecimento do empreendedor que estavam disponíveis, no entanto, afirmou que não fez uso dessas ferramentas. Esse tipo de ferramenta não foi importante para o processo de criação do spinoff, nem em seu desenvolvimento, como explica o entrevistado: "como nosso projeto é de tecnologia, não é tão necessário ter um laboratório, tipo laboratório de química, física, essas coisas, como é necessário quando o projeto é de química ou de física, não é tão relevante para gente".

O contato com professores da universidade auxiliou na elaboração de projetos para a empresa, como explicado pelo empreendedor A: "eu ia escrever um projeto de pesquisa para o FINEP, para projeto de fomento a inovação, aí eu pedi auxílio a eles na elaboração [...]". Contudo, a greve que ocorreu na universidade no ano de 2015 prejudicou a manutenção desse contato com os professores, atrapalhando o andamento de outros projetos, que deverão ser retomados no início de 2016. Os professores também auxiliaram na obtenção de recursos financeiros mais do que a própria universidade, como foi o caso do projeto do FINEP, citado anteriormente.

O processo de seleção para incubação da empresa se deu através de um plano de negócios elaborado pelos sócios. A experiência de estar na incubadora foi apontada como positiva e dentre as vantagens foram citadas o apoio físico, a realização de capacitações e a possibilidade de manter contato com outras empresas. No entanto, durante o período de incubação da empresa, a incubadora deixou o parque tecnológico por motivos ignorados, e o SergipeTec ficou encarregado dessas empresas, como explica o entrevistado: "O SergipeTec criou essa incubadora justamente para abarcar essas empresas que ficaram órfãs quando essa incubadora saiu, por motivos que eu não sei dizer [...]".

O empresário afirma que atualmente a incubadora não fornece um ambiente propício para as novas empresas: "a incubadora tá meio que 
abandonada, ela não desenvolve mais nenhum projeto, mais nenhuma capacitação, ela no máximo cobra aluguel". Segundo o Empreendedor A, um dos motivos pelos quais as empresas permaneceram na incubadora é porque nem todas possuem outro local para se instalarem. O abandono das empresas pela incubadora foi um dos motivos apontados para que a empresa tenha outro escritório, além de outras deficiências como o acesso precário à internet, como destacou o empreendedor $\mathrm{A}$ :

Basicamente a gente precisa ter computadores e acesso à internet, mas esse acesso que o parque tecnológico oferece é o pior possível, então é um dos motivos de a gente estar tentando sair de lá, porque se você não consegue nem ter acesso a internet, imagine outras coisas.

O contato com outras empresas, órgãos de fomento à pesquisa, fundos de investimento e outros contatos que poderiam ser disponibilizados à empresa não foram oferecidos pela universidade, como explica o empresário: "[...] não entraram em contato com a gente para oferecer esse tipo de ajuda", o que pode ter prejudicado o desenvolvimento da empresa, já que esses contatos são importantes para as empresas iniciantes.

Com o curso de mestrado em Propriedade Intelectual o empresário pretende desenvolver um estudo de caso sobre o registro de software e usar o exemplo da própria empresa, que pretende registrar o "IBAR", aplicativo para o segmento de bares e restaurantes. O mestrado também trouxe outros conhecimentos sobre o registro de patentes e marcas que devem ser utilizados pela empresa, como comenta: "[...] eu meio que tô tendo conhecimento técnico pra poder fazer isso né? Para poder atuar na proteção da propriedade intelectual dos ativos desenvolvidos pela empresa". Dentre as sugestões dadas pelo Empreendedor A, para que a participação da universidade contribua para a criação de novas empresas, estão:

[...] ter uma incubadora mais eficiente, poderia ter mais eventos relacionados a empreendedorismo, poderia ter uma equipe que auxiliasse na captação de recurso da empresa, que mostrasse como atrair investimento, que fornecesse laboratórios paras empresas utilizarem, dentro dos programas de graduação e de pós-graduação tivessem mais disciplinas relacionadas a empreendedorismo.

O empreendedor explica que existe uma deficiência cultural, pois os cursos de graduação e pós-graduação estão mais preocupados em formar alunos para prestarem concursos públicos e por isso não existe um estímulo por parte da universidade e dos professores para que esses alunos empreendam: "Eu acho que eles não estimulam os alunos a empreender, normalmente a ideia que fica é que empreender é uma coisa muito difícil e muito arriscada, que não vai dar certo, que você vai quebrar logo no primeiro ano, que você vai ter dor de cabeça [...]". O empresário ainda destaca:

[...] quando você é uma empresa que você tá desenvolvendo coisas de inovação, você precisa compartilhar o risco com alguém, seja com a universidade, seja com o Estado, na pessoa dos órgãos de fomento, das secretarias, você tem que compartilhar o risco com alguém. Se não tiver a participação da universidade, do Estado, fica muito difícil empreender, [...].

Quanto à diferença entre o apoio prestado por uma universidade pública e por uma privada à criação de novas empresas, o entrevistado acredita que a universidade pública oferece um apoio maior e que seja mais preocupada com as empresas, já que segundo ele: "[...] a universidade privada é muito 
voltada para graduar, graduou, acabou". No entanto, ele concorda que a universidade privada poderia oferecer mais estímulo ao mercado, mais oportunidades e mais contatos, requisitos essenciais para as empresas que estão entrando no mercado.

\section{O Caso da Lumentech}

A Lumentech é uma empresa de jogos eletrônicos criada em 2004 pelo "Empreendedor B", que concedeu a entrevista, na época aluno do curso de Ciência da Computação de uma universidade privada de Aracaju, e um colega recém-formado pelo mesmo curso. Os dois faziam parte de um grupo de estudos de games com outros colegas de curso, quando a recém-criada incubadora de empresas da universidade lançou um edital de seleção, o que chamou a atenção do sócio do entrevistado, como explica:

\footnotetext{
Ele viu a oportunidade e disse: "vamos fazer uma empresa", mesmo sem saber exatamente o que a gente ia ter que fazer, ou como ganharíamos dinheiro, por exemplo. Gostávamos de games, queríamos trabalhar com isso e não tinha empresa nenhuma nesse ramo em Aracaju. Então, por que não fazer a nossa?
}

Além dos dois sócios, um dos outros componentes do grupo se interessou pela ideia e decidiu fazer parte da sociedade. Apesar de participarem do grupo de estudos de jogos e serem alunos de um curso de computação, os jovens não possuíam ainda o conhecimento necessário para desenvolver os games, como destaca o entrevistado:

Não sabíamos desenvolver os jogos, a universidade não prepara a gente para isso. Então pesquisamos na internet, estudamos e testamos. Quando aprendemos a fazer um jogo de celular simples começamos a buscar alguém que pudesse pagar por esse serviço.

Antes mesmo da criação da empresa o terceiro sócio resolveu desistir da sociedade, devido a um problema de relacionamento. O Empreendedor B e o sócio restante, então, foram aprovados no edital de seleção da incubadora o que, para ele, foi a parte mais fácil, pois a inexperiência e carência de conhecimentos não se resumia às questões técnicas, mas também gerenciais, tendo em vista que o curso de Computação da universidade não ofereceu disciplinas voltadas ao empreendedorismo. A princípio, o sócio do entrevistado assumiu as funções gerenciais da empresa e ele se dedicou principalmente às técnicas.

O primeiro jogo produzido foi simples e nos anos iniciais a Lumentech também criou outros destinados a agências de publicidade. Em 2007, a empresa começou a internacionalizar, primeiramente a partir de um contato da cidade de Recife-PE feito pelo sócio. A Lumentech produzia os jogos e a empresa de Recife ficava responsável por publicá-los com operadoras no exterior. Após essa fase inicial da internacionalização, outros contatos foram formados, principalmente a partir de eventos internacionais de outsourcing, de forma que, atualmente, os clientes internacionais compõem a maior parte de sua base.

Quanto ao período de criação, destaca-se que o Empreendedor B visualiza diferenças entre seu perfil e do sócio. Na sua opinião, o sócio teve a iniciativa de aproveitar a oportunidade do edital da incubadora, pois ele nunca havia pensado em empreender. Essa diferença foi posteriormente relatada 
também quanto a uma posição mais voltada para a gestão da empresa: "ele (o sócio) era mais ativo nessa parte de empreendedorismo mesmo. Eu era uma negação". No entanto, em 2009 o sócio acabou saindo da empresa e o entrevistado teve que assumir as funções gerenciais, o que fez com que suas habilidades viessem à tona:

Quando o edital foi publicado e meu ex-sócio me convidou, meu objetivo era trabalhar na parte técnica, mas ele teve que se afastar da empresa e eu tive que assumir a parte gerencial. Foi quando eu me tornei empreendedor, porque até então eu era o sócio que trabalhava na parte técnica, não entendia de negócios.

Desde então, mesmo sem a participação do sócio que o estimulou a criar a empresa, a Lumentech continuou a se desenvolver. O Empreendedor B passou a se dedicar totalmente à gestão, participando de todos os eventos, atraindo clientes e projetos cada vez maiores. No momento da entrevista, a empresa estava envolvida em um grande projeto de um jogo para celular para um cliente internacional, envolvendo toda a equipe. Atualmente, o Empreendedor B continua como único sócio da empresa que possui treze colaboradores e produz jogos para clientes do Brasil, Finlândia, Índia, Japão, Estados Unidos, além de outros países. Em quase doze anos de experiência na área de games, a Lumentech criou de jogos simples para ações públicas de saúde a jogos sofisticados, envolvendo detecção de movimentos, por exemplo. Para o empreendedor, a tecnologia não é empecilho, mesmo que ainda seja desconhecida pelos seus desenvolvedores:

Se precisar fazer algum jogo de realidade virtual, com detecção de movimento, para celular, tablet, computador, videogame... a gente faz! Não temos medo de tecnologia. Mesmo que seja uma tecnologia com a qual ainda não tenhamos trabalhado, pesquisamos e descobrimos como fazer.

A motivação de abrir a empresa, como demonstrado anteriormente, partiu da identificação de uma oportunidade de empreender e outras oportunidades foram surgindo aos poucos. Como comenta o entrevistado, até mesmo a evolução de sua participação na empresa, de sócio desenvolvedor para gestor, foi ocasional:

Muita coisa que aconteceu na empresa foi ocasional. Se o edital não tivesse acontecido, não sei se a empresa teria sido criada. Eu, muito provavelmente, não teria empreendido, porque o curso não me dá esse direcionamento.

O Empreendedor B realçou que a universidade os estimulou a criar a empresa apenas de forma indireta, por meio da incubadora, e que eles tinham total autonomia em suas decisões. Mas, para ele, a incubadora em sua fase inicial aparentava não ter suporte da universidade, como um projeto pessoal do professor que a criou. Esse professor e, posteriormente, a secretária, procuravam estimular os alunos, apresentar os editais etc., como o entrevistado destaca: "Nunca teve muito apoio da universidade. A incubadora foi uma iniciativa muito pessoal do coordenador. Ele que moveu esforços para conseguir editais que pudessem financiar a construção do prédio, por exemplo".

Com o tempo, os outros alunos viam o sucesso da empresa e ficavam maravilhados, pois o entrevistado estava "trabalhando com games, vivendo disso, ganhando dinheiro com isso", mas esse status não era o mesmo durante o período da criação. Na verdade, ele diz que nunca havia se 
imaginado como empreendedor antes de 2004 e até achava que a palavra carregava um status muito negativo, pela incerteza de rendimentos e de carga horária, além da grande responsabilidade. Hoje, no entanto, ele diz que não vai viver sem a empresa, deixando evidente que existe um conflito entre as dificuldades de ser empreendedor e todas as recompensas como a satisfação pessoal:

Eu nunca vislumbrei "empreendedor" com um status muito bom. Até hoje eu não vejo, eu preferia ter um chefe porque o empreendedor é aquele que ganha menos, chega primeiro e sai por último (risos). Acho que todo empreendedor fala isso, apesar de que eu não saberia viver sem a empresa. As recompensas que eu tenho no trabalho são fenomenais, pagam qualquer coisa.

Segundo o Empreendedor B, nenhuma disciplina relacionada ao empreendedorismo foi disponibilizada pela instituição e até mesmo os eventos e seminários eram direcionados somente para a pesquisa ou parte técnica da computação. Os professores também não os auxiliaram porque, para o empreendedor, eles não imaginavam que a empresa fosse ter sucesso, já que desenvolvimento de jogos não é uma área com mercado em Aracaju, como explica: "Ninguém fazia ou estudava isso aqui, todo mundo aprendia a fazer software: sistemas de estoque, de $\mathrm{RH}$... e não era isso que a gente queria. Então nunca procuramos os professores, porque eles não teriam como ajudar a gente". Percebe-se então que a universidade não favorecia a busca de novas soluções de mercado.

Quanto à incubadora da universidade, essa viabilizava à empresa sua estrutura física: salas, banheiros, uma copa compartilhada, água encanada, energia elétrica, internet, estacionamento e segurança por uma pequena taxa mensal. Todos os alunos com empresa incubada poderiam acessar as salas em qualquer horário, com total liberdade para trabalhar de madrugada, se fosse preciso. Somente os móveis e computadores eram trazidos pelos alunos: "Na época, levamos prateleiras de madeira de casa, cadeiras de plástico que eu tirei da piscina lá de casa e uns computadores velhos que eu tinha".

Em relação ao suporte financeiro, a universidade, através da incubadora, avisava aos empreendedores sobre editais do CNPq, por exemplo, e sempre os auxiliava na submissão do projeto. Forneceu também um contador que os ajudou a criar a empresa, como destaca: "então, toda essa ajuda fez com que a gente focasse um pouco mais na parte tecnológica, como fazer jogos e como ganhar dinheiro com isso, do que se preocupar com abertura da empresa na JUCESE, por exemplo". Outra vantagem de ter feito parte de um processo de incubação foi o ambiente proporcionado pela incubadora como os contatos feitos com outras empresas e a emoção da "tentativa e erro", como detalha o empreendedor:

Além do apoio gerencial havia o ambiente "borbulhante", de estar todo mundo pensando em negócio e em como ganhar dinheiro com ele. Alguém tentava fazer algo e não funcionava, até que um tentava, conseguia e dividia essa experiência com a equipe. Também trabalhávamos em parceria com as outras empresas, se fosse necessário. Por exemplo, se em algum projeto a gente precisasse de artista ou de alguma coisa em que eles pudessem ajudar, trabalhávamos em conjunto. 
A incubadora também tentou estimular a empresa a patentear seus produtos, mas o Empreendedor $\mathrm{B}$ explicou que a patente não faz muito sentido na área de computação, tendo em vista que somente o código é patenteado e não a ideia. Assim, se alguém modificar uma linha de código, mesmo que produzindo o mesmo resultado, isso não se configura uma quebra de patente.

Atualmente, a empresa tem pouco contato com a sua universidade de origem. Desde o início, o entrevistado sentia como se a universidade não estivesse muito interessada em manter a incubadora ou as empresas lá. Como já dito, todo o apoio prestado pela incubadora foi uma iniciativa do coordenador que, posteriormente, teve auxílio de uma secretária. Foram quatro anos e meio de incubação, aproximadamente, e o momento da saída da empresa, para o entrevistado, foi quando esse relacionamento começou a esfriar. O contato com a universidade acontece apenas quando os professores convidam a Lumentech para participar de algum evento, fornecendo uma palestra ou um minicurso, por exemplo.

No entanto, apesar de não ser sua universidade de origem, a empresa participa de mais eventos da Universidade Federal de Sergipe, porque o Empreendedor B tem amigos pessoais que são professores do curso de computação, o que acabou por estreitar os laços entre a empresa e essa universidade. Para a empresa, esse contato é importante para chamar a atenção dos alunos para seu mercado, pois, como não existe mão de obra capacitada em desenvolvimento de jogos em Aracaju, os próprios desenvolvedores da empresa capacitam os novatos.

A universidade também não presta mais apoio financeiro, tendo em vista isso que era feito pela incubadora, a qual a empresa não participa. Atualmente a Lumentech consegue apoio financeiro de instituições como o SEBRAE, Sesc/Senac, APL Aracaju ou com a Rede Petrogás. Com a rede Sesc/Senac, inclusive, a empresa possui uma relação de mão dupla, pois já ministrou cursos para a mesma. Esses contatos com as redes, entretanto, foram possibilitados primeiramente pela incubadora e depois os empreendedores começaram a desenvolver sua própria rede de relacionamento.

Durante a incubação, a empresa participou de projetos de pesquisa do CNPq, com o auxílio do ITP - Instituto de Tecnologia e Pesquisa da universidade e com isso conseguiu contratar bolsistas PIBIC na época. Mesmo após o fim da incubação, a empresa participou de um grande projeto do FINEP, em parceria com empresas do SergipeTec e da área de petróleo. Ou seja, a empresa participou de projetos de pesquisa tanto em parceria com a universidade quanto somente em parceria com outras organizações. Contudo, o entrevistado afirma que nenhuma publicação acadêmica foi elaborada por eles nesses projetos.

Segundo o empreendedor, começar a empresa na universidade não foi só importante pelos contatos, projetos de pesquisa e apoio da incubadora, mas por passar uma certa credibilidade para a empresa que não era conhecida ainda no mercado: "o fato da gente estar na universidade ajudava. O endereço da gente era o da universidade, não éramos uma empresa qualquer, tínhamos o respaldo da Universidade". Hoje, ele não enxerga a empresa como inserida no ambiente acadêmico somente por participar de 
eventos e procurar a universidade para contratar mão de obra. Para ele, "a incubadora ganhou experiência com a nossa empresa, mas a universidade sempre foi muito antiquada em termos de investir em um projeto que não tem retorno garantido, como em um spin-off'.

Em resumo, o apoio prestado pela universidade foi deficiente na visão do empreendedor pois "o principal apoio não é o financeiro". O entrevistado acredita que as universidades públicas estimulam mais seus alunos a pesquisar e desenvolver novas ideias. O mercado da Lumentech é limitado em Sergipe, mas promissor fora do estado. Logo, o enrevistado avalia que quando o aluno é treinado somente para olhar para o usual, ele pode não enxergar outras oportunidades que possam ser bastante lucrativas. Quando procura por mão de obra, a empresa seleciona sempre alunos que possuem uma visão mais ampla e, por isso, a maioria dos seus colaboradores foi selecionada na Universidade Federal de Sergipe. Tal universidade, segundo o Empreendedor $B$, além de proporcionar uma formação mais ampla, conta com professores que procuram sempre saber como melhor capacitar seus alunos.

\section{Análise comparativa dos casos}

Nesta seção é apresentada a análise dos casos de forma comparativa, visando identificar a evolução e diferenças no apoio prestado pela universidade ao spin-off acadêmico nas duas fases de desenvolvimento consideradas no estudo: early e later stage.

\section{Early Stage}

Ao analisar comparativamente os spin-offs, verificou-se que a motivação para criação das empresas partiu da identificação de uma oportunidade: no caso da primeira empresa, a Avatar B2B, a possibilidade de desenvolver uma inovação para o segmento de bares e restaurantes; e para a segunda, a Lumentech, o lançamento do edital de seleção da incubadora da universidade no momento em que os empreendedores se interessavam pelo desenvolvimento de games. Em ambos os casos, os spin-offs, quando ligados às incubadoras, possuíam autonomia em suas decisões. Para a Avatar B2B, o apoio da universidade não foi determinante no processo de criação da empresa, já para a Lumentech, a universidade estimulou a criação do spin-off apenas de forma indireta, por meio da incubadora.

Aspectos relacionados ao empreendedorismo detectados nos dois casos, como identificação de oportunidades, propensão a assumir riscos e habilidade na mobilização de recursos foram apontados como fatores críticos de sucesso para os spin-offs acadêmicos (Steffensen et al., 2000). Outros autores também destacam que o comportamento empreendedor é vital para que as empresas de todos os tamanhos prosperarem em ambientes competitivos (Walter et al., 2006). 
A existência de incubadoras ligadas à universidade representa apoio ao spin-off durante seu desenvolvimento inicial, como mostrou Berbegal-Mirabent et al. (2015) e Borges et al. (2017), por facilitar o acesso a conhecimentos e a entidades de financiamento (Raupp \& Beuren, 2009). Tal suporte é de grande importância, tendo em vista que os spin-offs acadêmicos sofrem com acesso restrito aos mercados, falta de experiência e carência de conhecimento técnico e gerencial (Lockett \& Wright, 2005). No caso das empresas estudadas, as incubadoras auxiliaram no processo de criação, disponibilizando sua estrutura física e fornecendo contatos com outras empresas. Além disso, foram oferecidos alguns cursos de capacitação tanto para a Avatar B2B, quanto para a Lumentech. No entanto, o Empreendedor B alega que os cursos fornecidos não eram tão importantes, pois, como a maioria das empresas incubadas era do curso de Computação, a formação dos empreendedores carecia de conhecimentos mais específicos de gestão. Assim, essa formação só foi possível quando, por iniciativa própria, o Empreendedor B procurou o Empretec, ministrado pelo SEBRAE. Mesmo com essa limitação, destaca que o período de incubação foi essencial não só para a criação da empresa, mas pelo suporte financeiro e contábil e pelo ambiente da incubadora, que fomenta a inovação.

O contato com os professores pode influenciar as intenções empreendedoras dos estudantes, como foi apontado por Mueller (2011). Para a empresa Avatar B2B, esse contato possibilitou a elaboração de projetos importantes, como um projeto de pesquisa para o FINEP. Para o empreendedor dessa empresa, o auxílio dos professores foi mais importante na obtenção de recursos do que a própria universidade. No caso da Lumentech, o auxílio dos professores não foi solicitado já que, segundo o Empreendedor A, não possuíam conhecimento sobre desenvolvimento de jogos e os docentes também não acreditavam que a empresa teria sucesso, por pertencer a um segmento de mercado pouco explorado em Aracaju. No entanto, todo o suporte provido durante o período de incubação foi decorrente de um interesse pessoal de um professor do curso de Design, mentor e coordenador da incubadora, já que a universidade parecia não ter interesse nas empresas ou em sua incubação.

Para Fini et al., (2009), a universidade pode incentivar o envolvimento dos acadêmicos na criação de novas empresas por parte de seus alunos e o que mais incentiva a participação desses docentes é a melhoria do status acadêmico, possibilidade de contribuir com o desenvolvimento econômico do país e criar novas oportunidades de trabalho. Em nenhum dos dois casos estudados houve incentivo da universidade para a participação dos acadêmicos nas empresas. No caso da Avatar B2B os empreendedores foram responsáveis pelo contato com os professores quando achavam necessário; no caso da Lumentech, não houve contato.

Nos dois casos analisados não foi constatada a oferta de disciplinas relacionadas ao empreendedorismo pela universidade-mãe. O Empreendedor B acredita que a inserção dessas disciplinas no currículo poderia provocar os alunos pensarem sobre novos mercados. O Empreendedor A, sócio da Avatar B2B, afirma que as disciplinas 
de empreendedorismo por ele cursadas durante o curso de mestrado complementaram seus conhecimentos gerenciais e inspiraram novas ações da empresa. Assim, a adição de disciplinas de empreendedorismo no currículo dos cursos de computação poderia favorecer o desenvolvimento local através da multiplicação do conhecimento gerencial dos empreendedores, que foi constatado por Luz (2012).

Nenhuma das duas empresas solicitou ou obteve apoio de alunos. Em alguns momentos, a Lumentech atuou em parceria com outras empresas incubadas no mesmo local e afirma que essa relação foi bastante benéfica. O Empreendedor B afirmou posteriormente que mesmo que os outros alunos não soubessem desenvolver os jogos, talvez eles tivessem alguma contribuição para dar, com ideias ou sugestões. Dessa forma, seria interessante que as incubadoras estimulassem a relação das empresas incubadas com os alunos da universidade de origem, tendo em vista que o networking da universidade pode ser benéfico para a empresa em formação (Bailetti, 2011) e para estimular novos alunos a empreender.

A estrutura física provida pela incubadora da universidade foi crucial para a Lumentech, logo após sua criação e até o fim de seu período de early stage, culminando com sua saída da incubadora. Para a Avatar B2B, o baixo valor cobrado pelo aluguel e a disponibilização do espaço físico para a sede da empresa foram determinantes para sua sobrevivência na fase inicial da empresa. Como pertencentes a uma incubadora em sua fase de criação, a disponibilização de infraestrutura por um aluguel abaixo do mercado é uma forma de suporte descrito na literatura como bastante oportuna (Hoffman, Mais, \& Amal, 2010).

O acesso a recursos financeiros, principalmente no início da empresa, é essencial, pois auxilia a financiar o seu crescimento (Ndonzuau et al., 2002; Fini et al., 2009). Pode-se observar, através dos spin-offs estudados, que as universidades colaboraram de forma diferente na obtenção de recursos financeiros: a instituição privada participou de maneira mais ativa, fornecendo ajuda profissional aos empreendedores, na figura do contador, fator esse apontado por Berbegal-Mirabent et al. (2015) como facilitador na criação de empresas. Já na universidade pública, o auxílio do corpo docente solicitado pelos empreendedores foi mais determinante. No entanto, como mostra Bailetti (2011), para fomentar a atividade empreendedora, as universidades precisam seguir alguns princípios, como fornecer ajuda na obtenção de recursos externos, providenciar assistência empreendedora, obter acesso aos consumidores em potencial, parceiros e investidores. Todos esses aspectos não foram observados nos dois casos. O Quadro 04, a seguir, resume as formas de apoio encontradas nessa fase inicial nos dois spin-offs acadêmicos. 


\begin{tabular}{|c|c|c|}
\hline Apoio & Avatar B2B & Lumentech \\
\hline Motivação para criação da empresa & $\begin{array}{l}\text { Identificação de uma oportunidade, a } \\
\text { partir da possibilidade de desenvolver uma } \\
\text { inovação. }\end{array}$ & $\begin{array}{l}\text { Identificação de uma oportunidade, a partir } \\
\text { do lançamento do edital de seleção da } \\
\text { incubadora da universidade. }\end{array}$ \\
\hline Incubadora & $\begin{array}{l}\text { Auxiliou a empresa em seu processo de } \\
\text { criação, disponibilizando estrutura física e } \\
\text { fornecendo contatos com outras empresas, } \\
\text { além de cursos de capacitação. }\end{array}$ & $\begin{array}{l}\text { Auxiliou a empresa em seu processo de } \\
\text { criação, disponibilizando estrutura física e } \\
\text { fornecendo contatos com outras empresas, } \\
\text { além de cursos de capacitação. }\end{array}$ \\
\hline Contato com os professores & $\begin{array}{l}\text { Possibilitou a elaboração de projetos da } \\
\text { empresa. }\end{array}$ & $\begin{array}{l}\text { Aconteceu apenas com um professor, } 0 \\
\text { coordenador da incubadora. }\end{array}$ \\
\hline Oferta de disciplinas de empreendedorismo & $\begin{array}{l}\text { Não foram ofertadas disciplinas } \\
\text { relacionadas à temática durante o curso de } \\
\text { graduação do empreendedor, somente no } \\
\text { curso de mestrado. }\end{array}$ & $\begin{array}{l}\text { Não foram ofertadas disciplinas } \\
\text { relacionadas a temática. }\end{array}$ \\
\hline Apoio dos alunos & Não buscou a participação de alunos. & Não buscou a participação de alunos. \\
\hline $\begin{array}{l}\text { Disponibilizar infraestrutura: laboratórios, } \\
\text { equipamentos }\end{array}$ & Auxiliaram a empresa em sua fase inicial. & $\begin{array}{l}\text { Foi crucial para a empresa, após sua } \\
\text { criação e até sua saída da incubadora. }\end{array}$ \\
\hline $\begin{array}{l}\text { Auxílio para recursos externos, acesso a } \\
\text { consumidores, parceiros e investidores }\end{array}$ & $\begin{array}{l}0 \text { auxílio do corpo docente da universidade } \\
\text { foi mais determinante. }\end{array}$ & $\begin{array}{l}\text { A universidade participou de maneira mais } \\
\text { ativa e forneceu ajuda profissional aos } \\
\text { empreendedores. }\end{array}$ \\
\hline
\end{tabular}

Quadro 04: Apoio prestado pelas universidades aos spin-offs acadêmicos no early-stage

Fonte: Elaborado pelas autoras (2017).

\section{Later-stage}

Para a Avatar B2B, atualmente a universidade não participa ou presta qualquer tipo de apoio e a incubadora não proporciona cursos, eventos ou promoção de editais de auxílio financeiro. Por esses motivos, o Empreendedor A pretende deixar a incubadora e procurar outro local para instalar a empresa. Já para a Lumentech, as principais formas de apoio fornecidas pela incubadora (financeiro, contábil, de infraestrutura etc.) cessaram no momento em que a empresa deixou a mesma, o que coincidiu com o início da fase later stage e, atualmente, seus empreendedores só mantém contato com a universidade para participar de eventos ou quando necessitam de mão de obra.

Com relação ao apoio prestado pelas incubadoras das universidades, percebe-se que a variação entre uma empresa e outra é estreita e alusiva à instituição de origem e não à fase de desenvolvimento. A universidade privada, mesmo sendo relatada pelo entrevistado como mais ausente durante a criação, deu suporte à empresa durante a fase de later stage. Já a universidade pública deixou as empresas incubadas nas mãos do SergipeTec e não demonstraram mais interesse por elas. No entanto, essa postura não pode ser relacionada ao modelo de universidade (pública ou privada), mas à percepção de que o empreendedorismo acadêmico pode ser uma forma de transferência de tecnologia ou de desenvolvimento, tanto econômica local quanto universitária. 
As redes de contato fornecidas pela incubadora desempenharam papéis diferentes nos dois casos. No caso da Lumentech, elas foram fundamentais para despertar nos empreendedores a necessidade e importância de tais contatos, além de mostrar como consegui-los. Foi um "pontapé inicial" para que terminada a fase early stage, o empreendedor pudesse buscar novos contatos sem nenhum auxílio ou dificuldade. Já a Avatar B2B adotou uma postura mais autônoma em relação aos seus contatos, desde o momento da criação até o presente.

Quanto ao registro de patentes, a situação foi diferenciada nas duas empresas. Enquanto a Avatar B2B pretende atuar na proteção da propriedade intelectual dos ativos desenvolvidos pela empresa no futuro graças ao conhecimento do seu criador sobre o processo de registro proporcionado através de seu curso de mestrado, para a Lumentech não existe necessidade de patentear seus produtos, já que de acordo com o Empreendedor B, produtos semelhantes podem ser desenvolvidos sem que isso se configure uma quebra de patente. Assim, mesmo o registro de patentes sendo, tradicionalmente, considerado um indicador de crescimento dos spin-offs acadêmicos (Clarysse et al., 2007), esse índice não deve ser aplicado a todas as empresas de tecnologia, por não conseguir validar o desenvolvimento de todas as empresas do setor.

Os empreendedores também apontaram sugestões para que a participação da universidade seja mais satisfatória e contribua para a criação de novas empresas. Os dois concordam que mais disciplinas na área de empreendedorismo deveriam ser ofertadas. Para o Empreendedor $B$, as universidades particulares precisam desenvolver uma visão mais ampla do mercado, buscando criar novas soluções, e não somente formar profissionais que irão atuar no mercado local. Para o Empreendedor A, a universidade poderia realizar mais eventos sobre empreendedorismo, ter uma incubadora mais ativa e profissionais mais capacitados, que mostrassem como atrair investimentos para a empresa, além de estimular os alunos a empreender.

Sobre a diferença entre o apoio da universidade pública e da universidade privada, ambos os empreendedores acreditam que a universidade pública ofereça um apoio maior. Para o Empreendedor B, a universidade pública estimula os alunos a pesquisar, a desenvolver coisas novas, requisitos que podem levar os estudantes a identificar oportunidades inovadoras $e$ lucrativas. O Empreendedor A, da Avatar B2B, acredita que a universidade pública se preocupa mais com as empresas, enquanto a instituição privada está mais preocupada em formar os estudantes. No entanto, ele também acredita que a universidade privada pode oferecer mais estímulo ao mercado, contatos e oportunidades, o que corrobora a afirmação de Belenzon e Schankerman (2007), que consideram as universidades privadas como as mais orientadas ao mercado. O Quadro 05, a seguir, apresenta um resumo das formas de apoio prestadas pela universidade no later-stage. 


\begin{tabular}{lll}
\hline \multicolumn{1}{c}{ Apoio } & \multicolumn{1}{c}{ Avatar B2B } & Lumentech \\
\hline Participação da universidade & Não participa do momento atual da & Não participa do momento atual da \\
empresa. & empresa. \\
Incubadora & Ainda está na incubadora. & Já deixou a incubadora. \\
& Busca seus contatos de forma autônoma & Fez uso dos contatos da incubadora e \\
Redes de contato & desde o momento de criação até 0 & atualmente busca seus contatos por conta \\
& presente. & própria. \\
& Não possui patentes até o momento, mas & Não possui patentes até o momento e não \\
Patente & pretende proteger os ativos da empresa no & considera registrar os produtos da empresa. \\
& futuro. & 0 empreendedor acredita que a \\
& 0 empreendedor acredita que a & universidade pública estimula os alunos a \\
& universidade pública se preocupa mais & pesquisar e que pode levar os estudantes \\
Diferença entre o apoio da universidade & com as empresas, enquanto a instituição \\
pública e da universidade privada & privada está mais preocupada em formar os & a identificar oportunidades inovadoras e \\
& estudantes. & lucrativas. \\
\hline
\end{tabular}

Quadro 05: Apoio prestado pelas universidades aos spin-offs acadêmicos no later-stage

Fonte: Elaborado pelas autoras (2017).

\section{Conclusões e Recomendações}

O objetivo deste estudo foi analisar as formas de apoio concedido pelas universidades nas diferentes fases de desenvolvimento de spin-offs acadêmicos na cidade de Aracaju-SE. Pode-se observar que, durante a fase early stage, o apoio fornecido pelas universidades às empresas foi semelhante e deficiente. Dessa forma, não foi observado participação ativa da instituição de ensino na obtenção de recursos, essencial na criação da empresa (Fini, Grimaldi, \& Sobrero, 2009; Ndonzuau et al., 2002); na disponibilização de contatos, facilitando a troca de experiências e o acesso à empreendedores experientes (Nicolaou \& Birley, 2003; Mueller, 2011); ou na oferta de disciplinas voltadas ao empreendedorismo. O mérito das universidades consistiu apenas na disponibilização das incubadoras e, através delas, cursos de capacitação e infraestrutura, corroborando que a presença das mesmas fomenta a criação de spin-offs (O'Shea et al., 2005).

Comparando-se o apoio concedido na fase later stage por cada uma das instituições, o apoio prestado pela universidade privada foi um pouco mais satisfatório que aquele disponibilizado pela pública. Esta última, ainda entra em contato com o spin-off para participar de eventos como palestras, demonstrando, assim, algum desejo em estimular o empreendedorismo na instituição. Desse modo, no futuro, a universidade privada pode se beneficiar de uma melhor capacitação de seus empreendedores acadêmicos (Luz, 2012).

$\mathrm{Na}$ visão dos empreendedores entrevistados não houve troca de conhecimentos, de forma a desenvolver tanto a universidade quanto o spin-off. Treibich et al. (2013) identificaram duas visões dicotômicas quanto à evolução do relacionamento entre a universidade e seus spin-offs. $\mathrm{Na}$ primeira, há um relacionamento unilateral de transferência de conhecimento 
da universidade para a academia e, devido a isso, não existe necessidade de que essa relação seja expandida para além da fase inicial de incubação. A segunda defende que não há transferência de conhecimento da academia para a indústria, mas sim um conhecimento interativo coproduzido, o que garante a necessidade de uma interação contínua entre os dois, que se mantém durante a later stage.

Entende-se que este estudo atenda a uma lacuna da literatura ao abordar três aspectos pouco explorados (Pirnay \& Surlemont, 2003; Berbegal-Mirabent et al., 2015; Ferreira et al., 2017), provendo maior compreensão das formas de apoio concedido pelas universidades aos spin-offs acadêmicos em duas fases de desenvolvimento. Por meio da análise conduzida, pode-se inferir que as universidades estudadas, independente da forma de financiamento, colocam-se em posição de passividade quanto aos seus spin-offs. Desse modo, ainda que limitada pela validação externa (Yin, 2015) esta pesquisa aponta, como implicação prática, a necessidade de conscientizar as universidades sobre a importância do estímulo ao empreendedorismo e do suporte da universidadeaos primeiros anos do spin-off, que são os mais críticos para a empresa (Ndonzuau et al., 2002). Como implicação gerencial, indica-se que essa conscientização deve basear-se nos fatores apontados pela literatura como estimulantes para a geração de spin-offs por parte da universidade, sendo eles: políticas próprias, criação de um contexto que facilite a inovação, desenvolvimento de pesquisas de excelência e de um laboratório de transferência de tecnologia (Ramaciotti \& Rizzo, 2014). Assim, sugere-se que as universidades contribuam de forma mais ativa com a transferência de tecnologia (Gübeli \& Doloreux, 2005), desenvolvimento econômico (Bathelt, Kogler, \& Munro, 2010; O'Shea, Chugh, \& Allen, 2008; Soetanto \& Van Geenhuizen, 2015; Vincett, 2010) e geração de empregos (Carayannis et al., 1998; Pérez \& Sánchez, 2003; Steffensen et al., 2000; Walter et al., 2006) propiciados pelos spin-offs. Sugere-se ainda que futuros estudos envolvam um maior número de casos abordados, incluindo mais empresas nas fases de early e later stage, de diferentes universidades, com o intuito de enriquecer a análise.

\section{Deferências}

Andersson, M., \& Klepper, S. (2013). Characteristics and performance of new firms and spinoffs in Sweden. Industrial and corporate change, 22(1), 245-280.

Bailetti, T. (2011). Fostering student entrepreneurship and university spinoff companies. Technology Innovation Management Review, 1(1), 7-12.

Bathelt, H., Kogler, D. F., \& Munro, A. K. (2010). A knowledge-based typology ofuniversity spin-offs in the context of regional economic development. Technovation, 30(9), 519-532.

Bekkers, R., Gilsing, V., \& Van Der Steen, M. (2006). Determining Factors of the Effectiveness of IP-based Spin-offs: Comparing the Netherlands and the US. The Journal of Technology Transfer, 31(5), 545-546.

Belenzon, S., \& Schankerman, M. (2007). The impact of private ownership, incentives and local development objectives on university technology transfer performance. London: Centre for Economic Performance. 
Berbegal-Mirabent, J., Ribeiro-Soriano, D. E., \& García, J. L. S. (2015). Can a magic recipe foster university spin-off creation?. Journal of Business Research, 68(11), 2272-2278.

Bercovitz, J., \& Feldman, M. (2006). Entpreprenerial universities and technology transfer: A conceptual framework for understanding knowledge-based economic development. The Journal of Technology Transfer, 31(1), 175-188.

Bernstein, A. T., \& Carayannis, E. G. (2012). Exploring the value proposition of the undergraduate entrepreneurship major and elective based on student self-efficacy and outcome expectations. Journal of the Knowledge Economy, 3(3), 265-279.

Bezerra, É. D., Borges, C., \& Andreassi, T. (2017). Universities, local partnerships and the promotion of youth entrepreneurship. International Review of Education, 63(5), 703-724.

Boardman, P. C., \& Ponomariov, B. L. (2009). University researchers working with private companies. Technovation, 29(2), 142-153.

Borges Jr, C. V., Filion, L. J., \& Simard, G. (2010). Estudo comparativo entre o processo de criação de empresas tecnológicas e o de empresas tradicionais. RAlRevista de Administração e Inovação, 7(2), 3-21.

Borges, C., \& Filion, L. J. (2013). Spin-off process and the development of academic entrepreneur's social capital. Journal of technology management \& innovation, 8(1), 21-34.

Borges, C., Filion, L. J., \& Simard, G. (2008). Jovens empreendedores e o processo de criação de empresas. RAM. Revista de Administração Mackenzie, 9(8), 39-63.

Borges, M. R., Porto, G. S., \& Dias, A. A. (2017). Empresas spin-offs geradas no campus da USP de São Paulo: características e impactos econômicos. Revista de Administração, Contabilidade e Economia da Fundace, 8(2).

Bryman, A., \& Bell, E. (2015). Business research methods. Oxford University Press, USA.

Callan, B. (2000). Generating spin-offs: evidence from across the OECD. STI-Science Technology Industry Review, (26), 13-56.

Carayannis, E. G., Rogers, E. M., Kurihara, K., \& Allbritton, M. M. (1998). High-technology spin-offs from government R\&D laboratories and research universities. Technovation, 18(1), 1-11.

Clarysse, B., Wright, M., \& Van de Velde, E. (2011). Entrepreneurial origin, technological knowledge, and the growth of spin off companies. Journal of Management Studies, 48(6), 1420-1442.

Clarysse, B., Wright, M., Lockett, A., Mustar, P., \& Knockaert, M. (2007). Academic spin-offs, formal technology transfer and capital raising. Industrial and Corporate Change, 16(4), 609-640.

Clarysse, B., Wright, M., Lockett, A., Van de Velde, E., \& Vohora, A. (2005). Spinning out new ventures: a typology of incubation strategies from European research institutions. Journal of Business venturing, 20(2), 183-216.

Costa, L. B., \& Torkomian, A. L. V. (2008). Um estudo exploratório sobre um novo tipo de empreendimento: os spin-offs acadêmicos. RAC-Revista de Administração Contemporânea, 12(2), 395-427. 
Dahlstrand, A. L. (1997). Growth and inventiveness in technology-based spin-off firms. Research policy, 26(3), 331-344.

Di Gregorio, D., \& Shane, S. (2003). Why do some universities generate more startups than others?. Research policy, 32(2), 209-227.

Djokovic, D., \& Souitaris, V. (2008). Spinouts from academic institutions: a literature review with suggestions for further research. The Journal of Technology Transfer, 33(3), 225-247.

Eisenhardt, K. M. (1989). Building theories from case study research. Academy of management review, 14(4), 532-550.

Ferreira, M. P., Reis, N. M. R., Paula, R. M., \& Pinto, C. S. F. (2017). Structural and longitudinal analysis of the knowledge base on spin-off research. Scientometrics, 112, 289-313.

Fini, R., Grimaldi, R., \& Sobrero, M. (2009). Factors fostering academics to start up new ventures: an assessment of Italian founders' incentives. The Journal of Technology Transfer, 34(4), 380-402.

Gilsing, V. A., Van Burg, E., \& Romme, A. G. L. (2010). Policy principles for the creation and success of corporate and academic spin-offs. Technovation, 30(1), 12-23.

Gras, J. M. G., Lapera, D. R. G., Solves, I. M., Jover, A. J. V., \& Azuar, J. S. (2008). An empirical approach to the organisational determinants of spin-off creation in European universities. International Entrepreneurship and Management Journal, 4(2), 187-198.

Gübeli, M. H., \& Doloreux, D. (2005). An empirical study of university spin-off development. European Journal of Innovation Management, 8(3), 269-282.

Harkema, S. J., \& Schout, H. (2008). Incorporating student-centred learning in innovation and entrepreneurship education. European Journal of Education, 43(4), 513-526.

Hess, S., \& Siegwart, R. Y. (2013). University Technology Incubator: Technology Transfer of Early Stage Technologies in Cross-Border Collaboration with Industry. Business and Management Research, 2(2), 22-36.

Hoffmann, M. G., Mais, I., \& Amal, M. (2010). Planejamento e gestão de parques científicos e tecnológicos: uma análise comparativa. Economia Global e Gestão, 15(3), 89-107.

Koster, S. (2006). Whose child?: how existing firms foster new firm formation. Ipskamp, Enschede.

Landry, R., Amara, N., \& Rherrad, I. (2006). Why are some university researchers more likely to create spin-offs than others? Evidence from Canadian universities. Research Policy, 35(10), 1599-1615.

Lockett, A., \& Wright, M. (2005). Resources, capabilities, risk capital and the creation of university spin-out companies. Research policy, 34(7), 1043-1057.

Lockett, A., Siegel, D., Wright, M., \& Ensley, M. D. (2005). The creation of spin-off firms at public research institutions: Managerial and policy implications. Research policy, 34(7), 981-993.

Lockett, A., Wright, M., \& Franklin, S. (2003). Technology transfer and universities' spin-out strategies. Small Business Economics, 20(2), 185-200.

LUZ, M. R. (2012). Fatores críticos no processo de criação dos spin-offs acadêmicos: 
o caso Tecnosinos. Dissertação de mestrado, Universidade Federal de Itajubá, Itajubá, MG, Brasil.

McAdam, M., \& McAdam, R. (2008). High tech start-ups in University Science Park incubators: The relationship between the start-up's lifecycle progression and use of the incubator's resources. Technovation, 28(5), 277-290.

Mueller, S. (2011). Increasing entrepreneurial intention: Effective entrepreneurship course characteristics. International Journal of Entrepreneurship and Small Business, 13(1), 55-74.

Mustar, P., Renault, M., Colombo, M. G., Piva, E., Fontes, M., Lockett, A., Wright, M., Clarysse, B., \& Moray, N. (2006). Conceptualising the heterogeneity of researchbased spin-offs: A multi-dimensional taxonomy. Research policy, 35(2), 289-308.

Ndonzuau, F. N., Pirnay, F., \& Surlemont, B. (2002). A stage model of academic spinoff creation. Technovation, 22(5), 281-289.

Nicolaou, N., \& Birley, S. (2003). Academic networks in a trichotomous categorisation of university spinouts. Journal of business venturing, 18(3), 333-359.

O'Shea, R. P., Chugh, H., \& Allen, T. J. (2008). Determinants and consequences of university spinoff activity: a conceptual framework. The Journal of Technology Transfer, 33(6), 653-666.

O'shea, R. P., Allen, T. J., Chevalier, A., \& Roche, F. (2005). Entrepreneurial orientation, technology transfer and spinoff performance of US universities. Research policy, 34(7), 994-1009.

Pérez, M. P., \& Sánchez, A. M. (2003). The development of university spin-offs: early dynamics of technology transfer and networking. Technovation, 23(10), 823-831.

Phan, P. H., Siegel, D. S., \& Wright, M. (2005). Science parks and incubators: observations, synthesis and future research. Journal of business venturing, 20(2), 165-182.

Pirnay, F., \& Surlemont, B. (2003). Toward a typology of university spin-offs. Small business economics, 21(4), 355-369.

Powers, J. B., \& McDougall, P. P. (2005). University start-up formation and technology licensing with firms that go public: a resource-based view of academic entrepreneurship. Journal of business venturing, 20(3), 291-311.

Ramaciotti, L., \& Rizzo, U. (2014). The determinants of academic spin-off creation by Italian universities. R\&D Management, 45(5), 501-514.

Rasmussen, E. (2006). Spin-off venture creation in a university context-An entrepreneurial process view. Bodo Graduate School of Business, 1-29.

Rasmussen, E. (2011). Understanding academic entrepreneurship: Exploring the emergence of university spin-off ventures using process theories. International Small Business Journal, 29(5), 448-471.

Rasmussen, E., Mosey, S., \& Wright, M. (2011). The evolution of entrepreneurial competencies: A longitudinal study of university spin-off venture emergence. Journal of Management Studies, 48(6), 1314-1345.

Raupp, F. M., \& Beuren, I. M. (2009). Programas oferecidos pelas incubadoras brasileiras às empresas incubadas. RAI-Revista de Administração e Inovação, 6(1), 83-107. 
Rickne, A. (2000). New technology-based firms and industrial dynamics evidence from the technological system of biomaterials in Sweden, Ohio and Massachusetts. Göteborg: Chalmers University of Technology.

Rothaermel, F. T., \& Thursby, M. (2005). Incubator firm failure or graduation: The role of university linkages. Research policy, 34(7), 1076-1090.

Saunders, M., Lewis, P., \& Thornhill, A. (2009). Research methods for business students. (5th ed.). England: Pearson Education.

Shane, S. A. (2004). Academic entrepreneurship: University spinoffs and wealth creation. United Kingdon: Edward Elgar Publishing.

Siegel, D. S., Waldman, D. A., Atwater, L. E., \& Link, A. N. (2003). Commercial knowledge transfers from universities to firms: improving the effectiveness of university-industry collaboration. The Journal of High Technology Management Research, 14(1), 111-133.

Siegel, D. S., Waldman, D., \& Link, A. (2003). Assessing the impact of organizational practices on the relative productivity of university technology transfer offices: an exploratory study. Research policy, 32(1), 27-48.

Siegel, D. S., Westhead, P., \& Wright, M. (2003). Assessing the impact of university science parks on research productivity: exploratory firm-level evidence from the United Kingdom. International journal of industrial organization, 21(9), 1357-1369.

Soetanto, D., \& Van Geenhuizen, M. (2015). Getting the right balance: university networks' influence on spin-offs' attraction of funding for innovation. Technovation, 36, 26-38.

Steffensen, M., Rogers, E. M., \& Speakman, K. (2000). Spin-offs from research centers at a research university. Journal of business venturing, 15(1), 93-111.

Treibich, T., Konrad, K., \& Truffer, B. (2013). A dynamic view on interactions between academic spin-offs and their parent organizations. Technovation, 33(12), 450-462.

Van Geenhuizen, M., \& Soetanto, D. P. (2009). Academic spin-offs at different ages: A case study in search of key obstacles to growth. Technovation, 29(10), 671-681.

Vanaelst, I., Clarysse, B., Wright, M., Lockett, A., Moray, N., \& S'Jegers, R. (2006). Entrepreneurial team development in academic spinouts: An examination of team heterogeneity. Entrepreneurship Theory and Practice, 30(2), 249-271.

Vincett, P. S. (2010). The economic impacts of academic spin-off companies, and their implications for public policy. Research Policy, 39(6), 736-747.

Vohora, A., Wright, M., \& Lockett, A. (2004). Critical junctures in the development of university high-tech spinout companies. Research policy, 33(1), 147-175.

Walter, A., Auer, M., \& Ritter, T. (2006). The impact of network capabilities and entrepreneurial orientation on university spin-off performance. Journal of business venturing, 21(4), 541-567.

Wright, M., Lockett, A., Clarysse, B., \& Binks, M. (2006). University spin-out companies and venture capital. Research policy, 35(4), 481-501.

Yin, R. K. (2015). Estudo de Caso: Planejamento e Métodos. (4a ed.). Porto Alegre: Bookman. 